\title{
De toegevoegde waarde van individuele coaching op de werkplek
}

\author{
J.M.Wagter, C. Buis, F. Stam, M.A.W. Eckenhausen
}

\section{Samenvatting}

In het Medisch Centrum Alkmaar (MCA) werd individuele klinische coaching geïntroduceerd voor artsen in opleiding tot specialist (aios). De coaching richt zich op de CanMEDS domeinen communicatie, professionaliteit en samenwerking.

Op basis van theorieën, gericht op het impliciet en expliciet leren op de werkplek en op burn-out preventie, werd een driestaps coachingstraject voor aios ontwikkeld, waarin observatie op de werkplek een centrale rol inneemt. De eerste pilotgroep (tien aios) beoordeelde het traject positief. De in eerste instantie gepresenteerde vragen bij de intake werden in veel gevallen gerelateerd aan een communicatievraagstuk, zoals miscommunicatie met patiënten of conflicten met andere professionals. Het CanMEDS domein communicatie leek in eerste instantie de vragen te domineren. Tijdens de intake bleek echter in de meeste gevallen een onderliggend, meer divers probleem aan de orde te zijn, zoals extreem perfectionisme of gevoelens van onzekerheid. Deze gedistilleerde kernvragen vormden het uitgangspunt voor het coachingstraject, en bevonden zich naast communicatie ook op de domeinen van professionaliteit en samenwerking. De goede ervaringen van deelnemende aios leiden inmiddels tot meer aanmeldingen.

Gestructureerde coaching van aios levert naast genoemde bijdrage in de professionele ontwikkeling, een bijdrage aan burn-out preventie. Een kritische succesfactor bij het coachen van aios is de inzet van een objectieve, professionele coach. De effecten van deze vorm van coaching op de lange termijn zijn nog niet bekend. (Wagter JM, Buis C, Stam F, Eckenhausen MAW. De toegevoegde waarde van individuele coaching op de werkplek. Tijdschrift voor Medisch Onderwijs 2009;28(4):151-158.)

\section{Inleiding}

Burn-out onder assistenten in opleiding tot specialist (aios) en uitval tijdens deze opleiding zijn gespreksonderwerpen die regelmatig terugkeren onder opleiders. In het Medisch Centrum Alkmaar (MCA) zijn deze onderwerpen omgezet in concrete actie: individuele klinische coaching voor aios. Om burn-out voor te zijn en complexe problematiek bespreekbaar te maken, kan de aios onder begeleiding van een coach werken aan de persoonlijke ontwikkeling en aan de actuele thema's binnen de opleiding, zodat in de opleidingsjaren (en daarna) blijvend kan worden geprofiteerd van deze investering.
Dit artikel gaat achtereenvolgens in op de aanleiding, de theoretische achtergrond en de praktische uitvoering van individuele klinische coaching voor aios. Tevens worden de eerste resultaten van deze coaching in het MCA beschreven.

\section{Aanleiding}

De invoering van de CanMEDS rollen vraagt naast nieuwe leerpaden in de basisopleiding, ook om interventies in het leren op de werkplek van zowel aios als medisch specialisten. Het competentiegericht denken doet in toenemende mate een beroep op vaardigheden die weliswaar al (deels) aanwezig zijn, maar die door 
explicitering ook gewicht krijgen in het algehele functioneren.

Voor de opleider is de basisvaardigheid in communicatie en omgaan met patiënten een andere dan de vaardigheid om een aios in de juiste richting te begeleiden. De behoeften van de aios op dit gebied komen niet altijd overeen met wat de opleider kan bieden, zeker niet wanneer het gaat om meer complexe thema's, zoals vergaand perfectionisme of een kantelende werkprivé balans. De vraag is of het professioneel kunnen begeleiden van deze thema's tot de competenties van de opleider moet behoren. In het MCA is men van mening dat omgaan met deze meer complexe persoonlijke thema's, die mogelijk kunnen leiden tot burn-out of uitval in de opleiding, geen primaire competentie van een opleidend medisch specialist hoeft te zijn. Het waarnemen van situaties die extra aandacht behoeven, is wel voor de opleider weggelegd. Een 'niet pluis gevoel' bij het functioneren van een aios, kan al voldoende zijn.

Om toch vroegtijdig in te kunnen grijpen en professionele ondersteuning te bieden, is het concept van individuele klinische coaching geïntroduceerd. Individuele klinische coaching is een één op één coachingstraject, waar bij het vaststellen van de inhoud van de gesprekken (de observatie van) het werk van de aios in de klinische praktijk het uitgangspunt is.

\section{Theoretische achtergronden}

Bij het ontwikkelen en inzetten van klinische coaching is uitgegaan van wetenschappelijk onderzochte en zo mogelijk 'evidence based' elementen. Resultaten van diverse onderzoeken naar burn-out, burnout preventie en het leren op de werkplek van professionals, vormden de basis voor de ontwikkeling van interventies.

\section{Burn-out}

Wanneer een persoon zich (vergaand) aanpast aan een verschil tussen eigen idealen en de dagelijkse werkelijkheid in de professie, kan dit leiden tot burn-out. Burnout is een vorm van chronische, werkgerelateerde stress en vaak het resultaat van hoge emotionele betrokkenheid in interpersoonlijke relaties (met bijvoorbeeld patiënten en collega's), overvolle werkweken, overuren en van een groot beroep op het beslissingsvermogen in lastige situaties. Deze factoren, eventueel in combinatie met persoonskenmerken, zoals faalangst of perfectionisme, kunnen fysieke en emotionele burn-out tot gevolg hebben. ${ }^{1-3}$ Het gevolg hiervan is dat gaandeweg prestaties verminderen en de kwaliteit van persoonlijke, collegiale en in dit geval ook van patiëntcontacten onder de situatie lijden. Dit zet een vicieuze cirkel in gang, die de gevoelens van (professionele) tekortkoming verder kan versterken.

Le Blanc et al. ${ }^{1}$ citeren de bevindingen van Maslach dat het regelmatig analyseren van werkgerelateerde gevoelens helpt bij het voorkomen van burn-out. Tevens vond Maslach dat burn-out cijfers lager zijn onder mensen die actief uiting gaven aan gevoelens, deze gevoelens deelden en analyseerden. De 'locus of control' (LOC) - de mate waarin iemand ervaart dat hij zijn omgeving kan beïnvloeden - speelt eveneens een rol. Mensen die het idee hebben dat ze het behalen van een doel in eigen hand hebben (interne LOC) presteren beter dan mensen met een externe LOC (die het behalen van een doel toeschrijven aan factoren buiten hun eigen invloed). Tevens zijn mensen met een interne LOC meer tevreden over hun baan en meer gemotiveerd.

Het is dan ook niet verrassend dat vooral interventies die de interpersoonlijke spanningen en emoties verlagen, en die een gevoel van controle over de situatie geven, 
een positieve bijdrage blijken te leveren aan de preventie van burn-out.

\section{Het expliciet maken van impliciet leren}

Bolhuis ${ }^{4}$ omschrijft leren als 'het voor een persoon tot stand komen van betekenis of van verandering van betekenis met een relatief duurzaam karakter'. Simons en Ruijters ${ }^{5}$ laten in hun model voor contextgebonden leren zien hoe leren een samenspel is van drie aspecten: het persoonlijk bewust worden van het ontbreken van (een deel van) een competentie, het (met hulp) expliciet maken van impliciete leermomenten (zodat het leerproces inzichtelijk en bespreekbaar wordt) en het bieden van de gelegenheid om het geleerde in de praktijk te oefenen, te ervaren en te verbeteren. Daarbij benadrukken zij dat een gevoel van veiligheid in het leerproces fundamenteel is, welke voortkomt uit een samenspel van verschillende reacties op de omgeving en van persoonlijke emoties. In het leerproces dienen emotionele processen ruimte te krijgen; naast de benodigde nieuwsgierigheid en motivatie zijn bijvoorbeeld ook groei van onzekerheid (ontdekken iets niet te kunnen) en toename van hernieuwd zelfvertrouwen (resultaat van leren) herkenbare processen die aandacht verdienen.

\section{Meer dan gedraging}

Het functioneren en leren van mensen in organisaties is een stroming in de onderwijskunde en psychologie op zich. Het voert dan ook te ver om in deze context volledig te willen zijn.

Het 'Model of Individual Behaviour and Results' (MARS-model) ${ }^{6}$ laat zien hoeveel factoren er minimaal meespelen in het ontstaan van (waarneembaar) gedrag en het behalen van resultaten: persoonlijkheid, waarden, verwachtingen, stress, emoties en attitude; alle grijpen aan op de persoonlijke motivatie en de mogelijkheden en verwachtingen die iemand in een bepaalde rol/functie heeft. Tot slot zijn specifieke situatiegebonden aspecten van invloed.

Het model maakt met deze zeer beknopte samenvatting in één oogopslag duidelijk dat ingrijpen op slechts één van deze factoren niet voldoende is om langdurige en intensieve verandering teweeg te brengen. Tevens dienen bij verandering de persoonlijke factoren voldoende aandacht te krijgen om zodoende (hernieuwde) motivatie te creëren. Dat houdt in dat o.a. persoonlijke overtuigingen, identiteit, vermogens en gedrag stuk voor stuk aandacht verdienen. Hierbij kan de natuurlijk selectieve aandacht een barrière vormen: onze hersenen filteren het te veel aan stimuli tot onze eigen behapbare werkelijkheid. Dit ontneemt ons echter ook in (stressvolle) situaties de kans om nieuwe perspectieven aan te nemen; de feedback van anderen kan hierbij behulpzaam zijn.

\section{Klinische coaching}

Wanneer we bovenstaande samenvatting in ogenschouw nemen, concluderen we dat interventie voor gewenste gedragsverandering meer dan alleen gedrag moet kunnen beïnvloeden. Al langere tijd is bekend dat coaching als educatief instrument voordelen biedt aan coaches. ${ }^{6-8}$ Coaching wint aan populariteit en heeft vele betekenissen gekregen. Begeleiding wordt heden ten dage al snel coaching genoemd, het lijkt daarom van belang het begrip in deze context nader toe te lichten.

In relatie tot de werkplek heeft coaching drie belangrijke functies ${ }^{9}$ : het bieden van partnerschap in het leerproces, het leveren van feedback op bekwaamheden en het analyseren van taakuitoefening op de werkplek. Coachen op de werkplek houdt in dat het (begin)thema waarmee de coach zich aanmeldt betrekking heeft op de werksituatie. In de coaching wordt gewerkt aan heldere doelen en resultaten. Er worden afspraken gemaakt over de wederzijde 
inspanningen tijdens het coachingsproces en het resultaat wordt geëvalueerd. ${ }^{10}$ Coaching in deze zin kan niet plaatsvinden in een hiërarchische relatie, maar wordt door een onafhankelijke en objectieve coach begeleid. De term 'klinisch' benadrukt dat de coaching zich in dit geval concentreert op praktijkobservaties en praktijkthema's.

Klinische coaching biedt de gelegenheid fricties in gedrag in relatie tot de omgeving en betrokkenen te bespreken. Onder begeleiding van de coach kan worden geanalyseerd welke factoren voor de aio de boventoon voeren, welke overtuigingen of vermogens daar mogelijk een rol bij spelen en welke alternatieven er zijn om verandering aan te brengen.

\section{Uitwerking in de praktijk}

Mede op basis van bovenstaande theorieën is gekozen voor werkplekcoaching en is een DrieStapsMethode ontwikkeld (zie Box 1). Ook is de keuze gemaakt voor een niet-medicus als coach, teneinde hiërarchische verhoudingen uit te sluiten. Tot slot is de coach een geschoold en ervaren begeleider/coach, in dit geval een psycholoog.

Box 1. DrieStapsMethode.

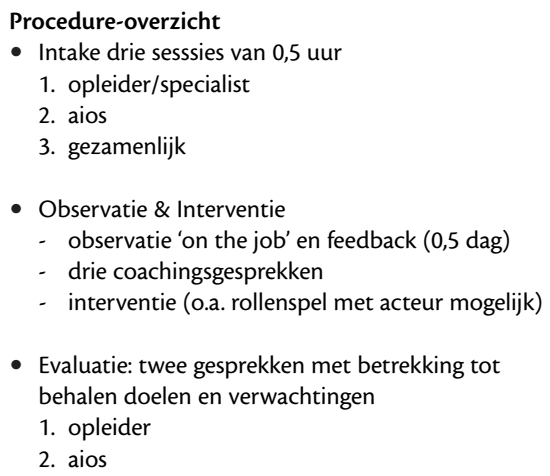

\section{DrieStapsMethode}

In het MCA heeft een eerste reeks van coachingsgesprekken met aios plaatsgevonden. Foreest Medical School verzorgt hier onderwijs en wetenschap. De aan de Medical School verbonden psycholoog begeleidt de coachingsgesprekken. De coaching focust zich in eerste instantie op drie CanMEDS competenties: communiceren, samenwerken en professioneel gedrag.

Het gehele proces bestaat uit drie stappen: intake, observatie \& interventie, evaluatie.

Intake: de opleider of aios kan telefonisch contact opnemen met de coach om een coachingstraject aan te vragen. De opleider heeft hier een signalerende functie, welke gerelateerd is aan het waarnemen en benoemen van (dis)functioneren van de aios. Ook de aios zelf kan hierin initiatief nemen. De intake bestaat uit twee individuele gesprekken, met aios en opleider, gevolgd door een gezamenlijk gesprek. Dit gezamenlijke gesprek is bedoeld ter observatie van de interactie tussen aios en opleider. Tevens biedt het de gelegenheid de problemen openlijk te bespreken onder leiding van de coach. Samen met de aios worden vervolgens voor het coachingstraject doelen en afspraken opgesteld. In deze fase is het van groot belang om zo snel mogelijk contact te leggen voor een eerste afspraak met aios en opleider. De aanmeldende partij is immers op het punt aangekomen dat ze gemotiveerd is en de noodzaak ziet om aan een oplossing te werken. Helaas is vaak al lang gewacht met het daadwerkelijk uiten van het probleem en wordt het coachingstraject als een laatste redmiddel aangegrepen.

Observatie \& interventie: in de meeste gevallen vormt 'on-the-job' observatie een onderdeel van het traject. De coach trekt een witte jas aan en loopt met de aios mee in zijn dagelijkse werkzaamheden. De ob- 
servaties geven veel informatie over het zichtbare gedrag van de aios en deze worden door de coach in een nagesprek voorzien van feedback. Hiermee start het bewustwordingsproces van achterliggende gedachten en gevoelens van de aios die tot het gedrag leiden. Vanuit deze bevindingen wordt een (psychologische) interventie aangereikt, passend bij de persoon. Het uitwerken hiervan gebeurt nog tijdens het coachingstraject, zodat de eerste effecten en moeilijkheden die verandering van gewoontes, gedachten en gedrag met zich meebrengen, besproken kunnen worden. Deze begeleidende coachgesprekken vinden met een regelmaat van eens per drie weken plaats. Bij interventies die voornamelijk ingrijpen op vermogensniveau is vaak oefening nodig. Hierbij kan gebruik worden gemaakt van rollenspelen met een ervaren acteur; soms wordt gekozen voor een externe training.

Evaluatie: in de laatste gesprekken vindt evaluatie en eventuele bijstelling van interventie(s) plaats. Enkele weken later volgt een individuele evaluatie met zowel opleider als aios. In dit gesprek wordt besproken of de gestelde doelen en verwachtingen naar tevredenheid behaald zijn.

\section{Resultaten}

In de pilot hebben tien aios gebruik gemaakt van de mogelijkheid van klinische coaching: vier vrouwen en zes mannen, afkomstig uit chirurgie (2), kindergeneeskunde (2), interne geneeskunde (2) en overige specialismen (4).

De eerste aanmelding werd in alle gevallen door de opleider gedaan. De door de opleider gesignaleerde problemen hadden alle betrekking op 'iets met de communicatie'. Na analyse in Stap 1 bleek uit specificatie van de hulpvraag dat $100 \%$ van de vragen gerelateerd was aan professioneel gedrag, $80 \%$ hiervan had ook betrekking op samenwerkingsvaardigheden en slechts $33 \%$ hiervan was eveneens een communicatievraagstuk. In Tabel 1 zijn de aanvankelijke doelstelling (zoals aangemeld door opleider) en de uiteindelijke doelstelling in kaart gebracht, aangevuld met de betreffende CanMEDS rollen waarop het doel betrekking heeft.

\section{Uitkomsten}

Van de tien aios gaven er negen aan dat hun werktevredenheid, met dank aan het coachingstraject, is toegenomen. Eén aios meldde een afgenomen werktevredenheid. Alle deelnemers rapporteerden een hoge tevredenheid over de gebruikte methoden met een positief effect op hun functioneren.

Het is niet voorgekomen dat een probleem werd gepresenteerd in samenhang met de CanMEDS rollen. Het feit dat alle aangemelde vraagstukken in eerste instantie als 'communicatieprobleem' werden gepresenteerd, kan samenhangen met het eerder genoemde gevolg van (dreigende) burnout: 'dat de prestaties verminderen en de kwaliteit van persoonlijke, collegiale en in dit geval ook van patiëntcontacten onder de situatie lijden.' Onderliggende problemen zoals loopbaanvraagstukken, faalangst of perfectionisme kunnen leiden tot zichtbaar (ongewenst) gedrag, dat in veel gevallen de aanleiding vormt tot het inschakelen van de coach.

Na de intake bleken de gestelde doelen vaak van persoonlijker aard dan 'leren communiceren'. De coach hielp bij het in kaart brengen van het onderliggende patroon of overtuiging, dat het praktische, zichtbare probleem veroorzaakte. $\mathrm{Na}$ analyse bleken deze patronen tot nu toe terug te brengen tot o.a. gevoelens van onzekerheid, extreem perfectionisme, job-adaptatie, miscommunicatie met patiënten en tot conflicten met andere professionals.

Teruggebracht tot de CanMEDS rollen viel op dat de meeste problemen, die in 
Tabel 1. Overzicht van de begeleidingsvragen en -doelstellingen.*

\begin{tabular}{|c|c|c|c|c|c|}
\hline & itiële vraag van de opleider & $\mathrm{Na}$ intake fase & 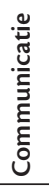 & 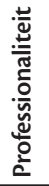 & 立 \\
\hline 1 & $\begin{array}{l}\text { Ondersteunen bij } \\
\text { beoordelingsgesprek }\end{array}$ & $\begin{array}{l}\text { Idem, plus het bieden van ondersteuning bij het } \\
\text { maken plan van aanpak voor de vervolgloopbaan }\end{array}$ & & $\bullet$ & $\bullet$ \\
\hline 2 & Betere stresshantering & $\begin{array}{l}\text { Leren een betere structuur en orde aan te brengen } \\
\text { in het werk }\end{array}$ & & $\bullet$ & $\bullet$ \\
\hline 3 & Rustig i.p.v. geagiteerd reageren & $\begin{array}{l}\text { Leren de emotie te temperen en het bewuster } \\
\text { kunnen kiezen van een mogelijke reactie }\end{array}$ & & $\bullet$ & \\
\hline 4 & $\begin{array}{l}\text { Korter en bondiger communiceren. } \\
\text { Communicatie beter afstemmen } \\
\text { op de ander }\end{array}$ & $\begin{array}{l}\text { Idem, plus beter kunnen omgaan met eigen irritatie } \\
\text { als blijkt dat boodschap niet wordt begrepen. } \\
\text { Structuur en doel in communicatie helder hebben }\end{array}$ & $\bullet$ & $\bullet$ & $\bullet$ \\
\hline 5 & $\begin{array}{l}\text { Communicatie met ouders } \\
\text { verbeteren }\end{array}$ & $\begin{array}{l}\text { Leren de communicatie beter afstemmen op ouders. } \\
\text { Leren relativeren: Minder kritisch zijn naar zichzelf } \\
\text { en anderen }\end{array}$ & $\bullet$ & $\bullet$ & $\bullet$ \\
\hline 6 & $\begin{array}{l}\text { Communicatie verbeteren met } \\
\text { ziekenhuismedewerkers, zodat } \\
\text { het aantal klachten vermindert }\end{array}$ & $\begin{array}{l}\text { Gedrag afstemmen (o.a. minder formeel zijn) als } \\
\text { de situatie daarom vraagt. Inzicht in het effect van } \\
\text { eigen gedrag op anderen en bij kunnen sturen. } \\
\text { Frustraties kunnen loslaten }\end{array}$ & & $\bullet$ & $\bullet$ \\
\hline 7 & $\begin{array}{l}\text { Communicatie verbeteren. } \\
\text { Onzekerheid verkleinen }\end{array}$ & $\begin{array}{l}\text { Inzicht krijgen in het effect van eigen gedrag op } \\
\text { anderen en helder krijgen waar het in de } \\
\text { communicatie soms scheef loopt. Handvatten } \\
\text { ontwikkelen voor bijsturing en verbetering } \\
\text { communicatie. Leren omgaan met emotionele } \\
\text { praktijkervaring en onzekerheidsgevoelens }\end{array}$ & $\bullet$ & $\bullet$ & $\bullet$ \\
\hline 8 & $\begin{array}{l}\text { Zich zeker neerzetten als } \\
\text { specialist en zich goed } \\
\text { presenteren bij sollicitatie- } \\
\text { gesprekken }\end{array}$ & $\begin{array}{l}\text { Idem, plus beter afstand kunnen nemen van } \\
\text { moeilijke beslissingen }\end{array}$ & & $\bullet$ & \\
\hline 9 & $\begin{array}{l}\text { Feedback leren te ontvangen } \\
\text { i.p.v. in de verdediging gaan. } \\
\text { Minder fel reageren }\end{array}$ & Idem & & $\bullet$ & $\bullet$ \\
\hline 10 & $\begin{array}{l}\text { Met verpleging goed kunnen } \\
\text { overleggen }\end{array}$ & $\begin{array}{l}\text { Tijdens overleg onderhandelingsruimte bieden. } \\
\text { Onzekerheid verkleinen door reële eisen aan } \\
\text { zichzelf te stellen/eigen energie in balans houden }\end{array}$ & & $\bullet$ & $\bullet$ \\
\hline
\end{tabular}

* met relevantie voor de competentiegebieden communicatie, professionaliteit en samenwerking. 
eerste instantie werden beleefd als communicatieproblemen, veel vaker van een andere orde bleken te zijn.

\section{Discussie}

De positieve uitkomsten kunnen mede bepaald zijn doordat de deelnemende aios en aanmeldende opleiders zich beiden openstelden voor de mogelijkheid van klinische coaching. Dit positieve uitgangspunt is een bekende succesfactor voor coachingstrajecten. Er werd in deze pilot niet gekeken naar de langetermijneffecten van klinische coaching.

Kijkend naar de redenen waarom het MCA koos voor klinische coaching - o.a. preventie van burn-out en het bieden van ondersteuning - worden zowel geslaagde werkvoortzettingen als een weloverwogen beslissing om te stoppen gezien als een positieve uitkomst voor de aios.

Met inachtneming van zowel de theorie als praktijk lijkt één kritische succesfactor onmisbaar: inzet van een professionele, objectieve en neutrale coach. De observaties van de coach mogen op geen enkele wijze invloed hebben op aanstelling en beoordeling. Deze garantie vormt een deel van de kern van veiligheid, met als doel een zo optimaal mogelijk coachingstraject te verkrijgen.

De coach is geen rolmodel, wel een klankbord voor de aios. Hij of zij helpt negatieve denktrends bij de aios te doorbreken en biedt vanwege het beroepsgeheim veiligheid. De coach geeft in geen geval informatie over de inhoud of het verloop van het traject aan de opleider en is in geen geval betrokken bij het bepalen van succes of falen van de aios in zijn opleiding. De coach is vaardig in luisteren, vragen stellen en specificeren en beschikt over ruime mogelijkheden en ervaringen met diverse (psychologische) interventies om de aios aan te zetten tot verandering van perspectief, overtuigingen, vermogens en gedrag. De positieve resultaten leiden inmiddels via onderlinge reclame tot een toename van spontane aanmeldingen, van zowel opleiders als aios.

De keuze voor coaching sluit aan bij een trend. In het bedrijfsleven is coaching al langere tijd gangbaar en ook in de zorg is dit in opkomst. ${ }^{11}$ Initiatieven zoals de loopbaancoaching van de $\mathrm{KNMG}^{12}$ of coaching van leerling-verpleegkundigen binnen de competentiegerichte opleiding zijn hier voorbeelden van.

De vraag is gerezen of deze individuele mogelijkheid niet dient te worden aangevuld met de mogelijkheid om in groepen te werken. Deze vraag heeft inmiddels geleid tot een intervisiepilot voor aios welke in de loop van 2009 van start gaat. Intervisie is een (begeleide) bespreking tussen collega's met een vergelijkbare functie en positie waarin concrete werksituaties op een systematische wijze worden besproken, zodat de deelnemers van elkaar leren en tot oplossingen komen.

\section{Toekomst}

Coaching wordt momenteel vooral nog gezien als 'laatste redmiddel'. Het kan voor opleider en aios een winstpunt zijn wanneer coaching - net als in het bedrijfsleven - als integraal onderdeel wordt beschouwd van een leerrelatie. Coaching helpt bij de persoonlijke ontwikkeling van de professional.

Meer onderzoek is nodig. Zo zou men in kaart kunnen brengen voor welke aios met name deze begeleidingsvorm zinvol is en of genderaspecten van invloed zijn op het wel of niet deelnemen aan coaching. Ook is interessant om te kijken uit welke specialismen de meeste aanmeldingen afkomstig zijn en welke mogelijke factoren hiermee samenhangen. Tot slot is het voor uitvoering in de praktijk nuttig om in kaart te brengen welke randvoorwaarden minimaal vereist zijn om coaching van 
aios als integraal onderdeel van de opleiding in te voeren en wat de langetermijneffecten van de interventie zijn.

\section{Literatuur}

1. Le Blanc Pascale, Hox J, Schaufeli W, Taris T, Peeters M. Take Care! The evaluation of a team based burnout intervention program for oncology care providers. Journal of Applied Psychology 2007; 92(1):213-227.

2. Thomas NK. Resident burnout. JAMA 2004;292 (23):2880-89.

3. Schaper Frank. Geen tijd voor burnout. Het verband tussen karakter, levensfase en stress. Schiedam: Scriptum; 2004. [No time for burnout. The relationship between character, stage of life and stress. Schiedam: Scriptum; 2004].

4. Bolhuis S. Leren en veranderen bij volwassenen. Een nieuwe benadering. Bussum: Coetinho; 2001. [Learning and change in adults. A new approach. Bussum: Coetinho; 2001].

5. Simons PR and Ruijters MCP. Learning Professionals: towards an integrated model. Professional learning: gaps and transitions on the way form novice to expert. Dordrecht/Boston/London: Kluwer Academic Publishers; 2004(2:306).

6. McShane SL,Von Glinow MA. Organizational Behaviour (4th ed.) Irwin; McGraw-Hill; 2008.

7. Kushnir $\mathrm{T}$ et al. The effects of a coaching project in nursing on the coaches' training motivation, training outcomes, and job performance: an experimental study. International Journal of Nursing Studies 2008;45:837-845.

8. Haan E de. Relationele coaching. Wegen naar meesterschap in helpende gesprekken. Assen: Van Gorcum; 2007. [Relational coaching. Roads to mastery in facilitating conversations. Assen: Van Gorcum; 2007].
9. Bergenhenegouwen G, Mooijman EAM, Tillema $\mathrm{HH}$. Strategisch opleiden en leren in organisaties. Groningen: Stenfert-Kroese; 2000. [Strategic teaching and learning in organisations. Groningen: Stenfert-Kroese; 2000].

10. Dijkstra T. (red.) Coachen als tweede beroep. Gedrag, gespreksvaardigheden en interventietechnieken. Zaltbommel: Thema; 2007. [Coaching as a second profession. Behaviour, interview skills and intervention techniques. Zaltbommel: Thema; 2007].

11. Baars M, Werf M van der. Anders leren, beter werken. Praktijkgericht leren en coachen in de zorg. Houten: Bohn Stafleu van Loghum; 2006. [Learn differently, work better. Learning and coaching for health care practice. Houten: Bohn Stafleu van Loghum; 2006].

12. Coaching: investeren in jezelf. Med Contact Nr. 52 22 december 2004. [Investing in yourself. Medical Contact nr. 52 - 22 december 2004].

\author{
De auteurs: \\ Drs. J.M. Wagter is onderwijskundige aan de Foreest \\ Medical School. \\ Drs. C. Buis is psychologe aan de Foreest Medical School. \\ Dr. F. Stam is internist en opleider interne geneeskunde \\ Medisch Centrum Alkmaar. \\ Dr. M.A.W. Eckenhausen is kinderarts en directeur van \\ de Foreest Medical School.
}

\section{Correspondentieadres:}

Dr. M.A.W Eckenhausen, Foreest Medical School, Medisch Centrum Alkmaar, postbus 501, 1800 AM Alkmaar. Tel.: 072-548 3703; e-mail:m.a.w.eckenhausen@mca.nl

Belangenconflict: geen gemeld

Financiële ondersteuning: geen gemeld

\section{Summary}

Alkmaar Medical Centre has introduced a programme offering residents individual clinical coaching based on three of the CanMEDS competencies: communicator, collaborator and professional. The 3-step coaching programme is based on theories of implicit and explicit workplace learning and prevention of burnout. Direct observation in the workplace is the pivotal feature of the programme. The evaluation of the pilot by the first group of ten residents was positive. Initially, the main problems of participants appeared to be related to communication, such as miscommunication with patients, conflicts with other professionals. The first interviews showed, however, that the underlying problems were more diverse, such as extreme perfectionism or feelings of uncertainty, which meant that coaching also related to 'professional' and 'collaborator' competencies. Participants reported high satisfaction with the approach used as well as positive effects on their functioning. This has resulted in an increase in enrolment in the programme.

Not only does the coaching programme promote residents' professional competencies, it also contributes to prevention of burnout. A key factor in the programme is an objective, professional coach. The long-term effects of the programme are not yet known. (Wagter JM, Buis C, Stam F, Eckenhausen MAW. The added value of individual coaching in the workplace. Dutch Journal of Medical Education 2009;28(4):151-158.) 